\section{Commentary: What's past is prologue: The story of pneumonectomy}

\author{
Ashok Muniappan, MD
}

\section{Antonio:}

Whereof what's past is prologue, what to come

In yours and my discharge

-William Shakespeare, The Tempest,

Act II, Scene i, Line 253

It may not always be apparent to us how far we have come in our clinical practice. For instance, the first successful pneumonectomy for lung cancer was performed 87 years ago, in 1933, by Dr Evarts A. Graham at Washington University's Barnes Hospital. ${ }^{1}$ The patient had a 75-day postoperative hospital stay that was complicated by a bronchopleural fistula but who made a complete recovery and survived for another 30 years. While there were 19 consecutive deaths after the first success, Dr Graham's operative mortality rate settled at $30 \%$. Persistence on the part of surgeons and their colleagues led to improved patient selection, operative technique, anesthesia, and postoperative care to the point where pneumonectomy is now possible with much less risk. What is surprising, then, is how little is known about the mortality rate beyond postoperative day 30. Although a few studies have studied the 90-day mortality rate for pneumonectomy, there is virtually no information regarding how the risk of readmission and mortality changes beyond 90 days.

Jones and colleagues ${ }^{2}$ performed an elegant analysis of how readmission and mortality rates changed throughout the first year after pneumonectomy for lung cancer at their institution. First, they report very good 30-day and 90-day operative mortality rates of $4.5 \%$ and $6.8 \%$, respectively. They note a steep decline in mortality rates after 7 days, with a nadir at 90 days. After that, there is a very gradual

\footnotetext{
From the Division of Thoracic Surgery, Massachusetts General Hospital, Boston, Mass.

Disclosures: Author has nothing to disclose with regard to commercial support.

Received for publication March 10, 2020; revisions received March 10, 2020; accepted for publication March 11, 2020; available ahead of print April 5, 2020.

Address for reprints: Ashok Muniappan, MD, Division of Thoracic Surgery, Massachusetts General Hospital, Founders 7, 55 Fruit St, Boston, MA 02114 (E-mail: amuniappan@mgh.harvard.edu).

J Thorac Cardiovasc Surg 2020;160:259-60

0022-5223/ $\$ 36.00$

Copyright (c) 2020 by The American Association for Thoracic Surgery

https://doi.org/10.1016/j.jtcvs.2020.03.116
}

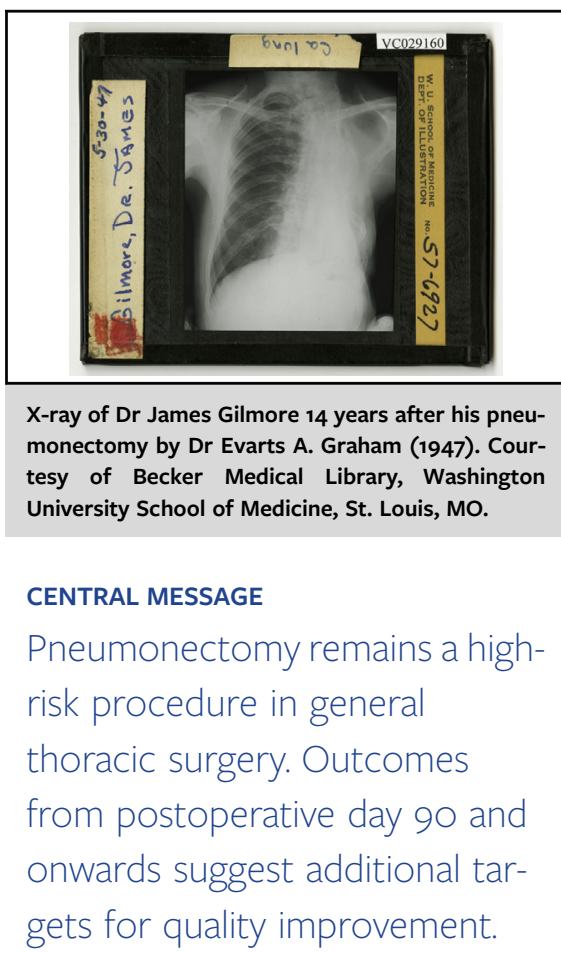

increase in mortality rate, mostly due to oncologic causes. Second, they noted the risk of readmission quickly declines in the first 2 weeks after discharge, nadirs at 4 months, and only starts to rise gradually at 8 months after discharge. Importantly, the authors were able to categorize the causes of death and readmission. Pulmonary causes are preponderant in the first 90 days, whereas oncologic causes become ascendant subsequently. The authors did not attempt multivariate analysis to determine the impact of putative risk factors for readmission and mortality; this was not their primary objective and the extant literature can fill in the gap. ${ }^{3}$

Dr Harold Urschel asserted that pneumonectomy "is a disease unto itself"; he was speaking about not only the early postoperative risk but also the physiologic impact on the patient beyond the traditionally reported postoperative period. Jones and colleagues do not prove this point, but their results suggest that even if a patient avoids early readmission or mortality, their prognosis is still guarded, with about a $20 \%$ risk of all-cause mortality after 1 year. It is a story of "glass half-full or empty"; multidisciplinary discussions should account for outcomes beyond 30 or 90 days when deciding whether pneumonectomy is reasonable. This has become all the more important as we wrestle with questions such as whether pneumonectomy ought to be performed for stage IIIA lung cancer, especially in the 
light of encouraging trial results with definitive chemoradiotherapy followed by immunotherapy. ${ }^{4}$

Blackstone and his colleagues ${ }^{5}$ published in 1986 their technique of "time-varying" analysis of survivorship and other events after cardiac surgery, which is used in the study by Jones and colleagues. It is almost exclusively used in cardiac surgery studies, and there appears to be only one other general thoracic surgery study that cites this statistical technique. ${ }^{6}$ Perhaps we shall see greater adoption of this manner of analysis as general thoracic surgeons direct increased attention to patient outcomes beyond the traditional 30 or 90 days.

The incidence of pneumonectomy for pulmonary resection is declining, likely as a result of lung cancers being diagnosed earlier, increased use of sleeve resection, and avoidance of pneumonectomy out of concern for inferior or equivalent outcomes compared with nonoperative options. If we are to improve outcomes after pneumonectomy and preserve its standing in our armamentarium, one place to start is by paying attention to the actual causes of readmission and mortality in the different periods after pneumonectomy. In the Online Data Supplement of Jones and colleagues, it is interesting to see that arrhythmia and cardiac arrest were the most common non-oncologic cause of death in the first year. Improved preoperative cardiac assessment or attention to cardiac function in the postoperative period, even beyond the 30-day point, could lead to improvement in outcomes.

The story of pneumonectomy is not over. Dr Graham and any number of our forebears would expect us to continue to refine this technique and improve on observed outcomes, even if we are using it less often. Having a total picture of patient outcomes beyond the early postoperative period will only bolster our ability to complete this task.

\section{References}

1. Horn L, Johnson DH. Evarts A. Graham and the first pneumonectomy for lung cancer. J Clin Oncol. 2008;26:3268-75.

2. Jones GD, Caso R, Dycoco J, Park BJ, Molena D, Huang J, et al. Time-varying analysis of readmission and mortality during the first year after pneumonectomy. J Thorac Cardiovasc Surg. 2020;160:247-55.e5.

3. Thomas PA, Berbis J, Baste JM, Le Pimpec-Barthes F, Tronc F, Falcoz PE, et al. Pneumonectomy for lung cancer: contemporary national early morbidity and mortality outcomes. J Thorac Cardiovasc Surg. 2015;149:73-82.

4. Antonia SJ, Villegas A, Daniel D, Vicente D, Murakami S, Hui R, et al. Overall survival with durvalumab after chemoradiotherapy in stage III NSCLC. $N$ Engl J Med. 2018;379:2342-50.

5. Blackstone EH, Naftel DC, Turner ME. The decomposition of time-varying hazard into phases, each incorporating a separate stream of concomitant information. J Am Stat Assoc. 1986;81:615-24.

6. Raja S, Schraufnagel DP, Blackstone EH, Murthy SC, Thota P, Thuita L, et al. Reintervention after heller myotomy for achalasia: is it inevitable? Ann Thorac Surg. 2019;107:860-7. 